\section{Raízes \\ Vol. 22, $\mathrm{N}^{\mathrm{o}} 01$, jan.-jun./2003}

Trabalho recebido em 09/10/2003

Aprovado para publicação em 10/04/2004
Jean-Philippe Tonneau

Pesquisadordo CIRAD, e-mail:tonneau@cirad.fr

Pedro Carlos Gama da Silva

Pesquisador da Embrapa Semi-Árido, e-mail: pgama@cpatsa.embrapa.br

\title{
APRENDIZAGEM COLETIVA E DESENVOLVIMENTO DA AGRICULTURA FAMILIAR NO SERTÃO DA BAHIA
}

\author{
RESUMO
}

O artigo apresenta uma experiência no Sertão baiano que privilegiou uma abordagem construtivista, integrando os diferentes atores em torno de um objetivo comum: o desenvolvimento e a melhoria das condições de vida da população local. No decorrer dos quinze anos da suas existências, a natureza e as formas das ações modificaram-se. Mas permaneceu a capacidade de adaptação social frente às importantes mudanças institucionais e sócio-econômicas dos últimos 30 anos. Partindo da análise histórica das evoluções, em particular das organizações sociais, os autores propõem algumas orientações de políticas publicas.

Palavras-chaves: Desenvolvimento local; organizações sociais, ação coletiva;

\section{COLLECTIVE LEARNING AND FAMILY FARMING DEVELOPMENT IN SERTÃO OF BAHIA}

\author{
ABSTRACT
}

This article presents a case study on a development initiative from the inland Sertão region of Bahia State (Brazil). This initiative can be characterised by its constructivist approach, integrating different social actors around a common objective: local development and improvement of livelihoods for local population. During the fifteen years of this initiative's existence, the nature and the format of its activities have changed substantially. With this, it managed to adapt to the important institutional and socio-economic changes that occurred in recent years. Starting with a historical analysis of these evolutions, in particular those concerning social organisations, the authors propose some guidelines for public policies.

Key-words: Local development; social organisations; collective action. 


\section{INTRODUÇÃO}

Massaroca é o nome de um pequeno distrito do município de Juazeiro, sertão da Bahia. A pequena região em torno da sede deste distrito foi, durante quinze anos, palco de uma série de ações de pesquisa, formação e apoio à Agricultura Familiar. Para tanto, inspirado em experiências de desenvolvimento local, foi elaborado um projeto no qual se associaram a Empresa Brasileira de Pesquisa Agropecuária (Embrapa); a Empresa de Assistência Técnica e Extensão Rural da Bahia (Emater-BA); a Associação de Desenvolvimento e Ação Comunitária (Adac) e o Centro de Cooperação Internacional em Pesquisa Agronômica para o Desenvolvimento (Cirad) ${ }^{1}$. Entretanto, os principais atores desta "história de desenvolvimento local" são agricultores e criadores de caprinos e ovinos que, em 1987, quando começou a intervenção das instituições de pesquisa e de extensão, estavam recém-organizados em associações comunitárias.

O distrito Massaroca, hoje, para muitos dos seus atores, é sinônimo de "Projeto Massaroca". Este termo genérico perpassa os conceitos de programas de intervenção, de sistemas de financiamento ou de convênios de cooperação. Além do projeto de cooperação Cirad-Embrapa, houve vários projetos de financiamento do Programa de Apoio ao Pequeno Produtor Rural (PAPP) e muitos outros projetos formais conduzidos pelas demais instituições que atuavam na região. A maioria dessas ações já terminou há algum tempo, mas o "Projeto Massaroca” continua vivo e em évolução.

Tanscorridos mais de quinze anos do início do Projeto, a sua permanência neste conceito é fruto de um processo que privilegiou uma abordagem construtivista, integrando os diferentes atores em torno de um objetivo comum: o desenvolvimento e a melhoria das condições de vida da população local. Procurou-se manter uma dinâmica interativa com base no diálogo, favorecendo o intercâmbio do "saber fazer" e de conhecimentos entre organizações dos produtores e instituições de pesquisa, formação e desenvolvimento.
Os atores mudaram. Algumas instituições do Estado foram praticamente substituídas pelas ações das ONGs e de uma cooperação direta que foi estabelecida entre os agricultores franceses e os de Massaroca. A natureza das ações modificou-se. A transformação técnica e os investimentos dos primeiros anos de intervenção perderam, relativamente, a importância para o manejo dos meios e dos recursos materiais e humanos disponíveis, a formação técnica e a educação dos anos subseqüentes.

Paralelamente, as relações sociais evoluíram no âmbito das comunidades. A trajetória dessa evolução pode ser expressa nos termos "das comunidades às associações e ao território". Eles traduzem mudanças nas formas de organização social e, também, na evolução da realidade e dos paradigmas do desenvolvimento, que o Brasil conheceu nestes últimos vinte anos, como : a negação total do tradicional como atrasado, a formação para modernização técnica competitiva e a revalorização dos saberes para construção de territórios específicos em função dos recursos disponíveis. Vale salientar que isso representou a marginalização, a integração econômica e o desenvolvimento sustentável.

Nesta evolução do enfoque de aprendizagem coletiva e de organização, qual foi o papel que o projeto desempenhou e procurou manter ao longo da sua existência? Quais foram as influências recíprocas entre a intervenção e a evolução da sociedade de Massaroca? Como se operaram os ajustes entre a dinâmica social interna e os intervenientes exteriores? São estas, entre outras, as questões que se pretende responder neste artigo. Para tanto, apresenta-se, a seguir, o contexto institucional do projeto, a realidade das comunidades e das associações no início do projeto, as ações do projeto numa primeira fase, as dificuldades desta fase de investimento e de construção e, finalmente, os novos rumos dados às ações.

$\mathrm{O}$ intuito é retratar aspectos de uma realidade que evoluiu e continua evoluindo rapidamente, no ritmo das transformações recentes que vêm ocorrendo no Nordeste. Espera-se que uma reflexão proveniente desta experiência antiga proporcione subsídios teóricos e praticas para o debate sobre o futuro da agricultura familiar e sobre os meios e formas de intervenções necessárias para a sua consolidação.

${ }^{1}$ A Embrapa participou através do seu Centro de Pesquisa Agropecuária do Trópico Semi-Árido (CPAT$\mathrm{SA}$ ), atualmente, Embrapa Semi-Árido. A Emater-BA deu origem à atual Empresa Baiana de Desenvolvimento Agropecuário (EBDA).

Raízes, Campina Grande, vol. 22, nº 01, p. 88-98, jan./jun. 2003 
90 Jean-Philippe Tonneau e Pedro Carlos Gama da Silva

\section{O CONTEXTO INSTITUCIONAL}

A experiência de Massaroca foi conduzida a partir de um contrato de cooperação entre o Cirad-Sar e a Embrapa Semi-Árido. Este Centro de pesquisa, criado em 1975, tinha entre seus objetivos a geração e a difusão das técnicas e tecnologias agronômicas necessárias ao desenvolvimento e à modernização dos estabelecimentos agrícolas do trópico semi-árido do Nordeste brasileiro.

Depois de uma fase de pesquisa em estação (19741980), calcada na geração e na adaptação de algumas tecnologias trazidas de outras zonas áridas (forragens, barragem subterrânea, cisternas, entre outras), o Centro se deteve a difundir tecnologias no meio real. O público alvo, no quadro do Projeto Sertanejo, era os pequenos produtores do Nordeste.

Para atingir este objetivo, um programa de pesquisa em meio real foi lançado na região em torno do município de Ouricuri, no oeste do estado de Pernambuco, a $200 \mathrm{~km}$ de Petrolina. Esta região de estudo, com uma superfície de $8.500 \mathrm{~km}^{2}$, foi escolhida devido à diversidade das situações agroecológicas que comportava e por ser considerada como uma regra representativa do conjunto do semiárido nordestino (Kilian, 1980; Mantovani et al., 1986).

Um trabalho minucioso de identificação dos recursos naturais e dos sistemas de produção realizou-se entre 1980 e 1986. Este trabalho tinha como finalidade caracterizar as diversidades ecológicas e sociais da região. Seis propriedades foram escolhidas para uma intervenção técnica denominada "Sistema Integrado de Produção", cujo objetivo era de resolver os problemas dessas propriedades.

A experiência, que começou em 1984, teve sua a primeira avaliação três anos depois. Tonneau (1987) apontou uma série de dificuldades:

- a escolha das técnicas limitou-se aos domínios das competências dos pesquisadores da Embrapa Semi-Árido e não atendiam ao conjunto das necessidades dos produtores;

- as tecnologias tinham sido elaboradas na estação experimental, em condições ideais, e eram marcadas por uma vontade de transformação e de modernização;

- a adaptação consistia em recriar, artificialmente, estas condições ótimas por uma injeção significativa de capital, incompatível com as condições das políticas agrárias existentes;

- Apesar de alguns sucessos técnicos, a difusão ficava limitada.

Raízes, Campina Grande, vol. 22, nº 01, p. 88-98, jan./jun. 2003
As conclusões da avaliação apontam para a necessidade de elaborar uma proposta mais ambiciosa, envolvendo a associação dos produtores na definição de inovações para modificar o ambiente institucional e social necessário à adoção das tecnologias. Esta proposição encontrou a adesão da Emater-BA, que manifestava a vontade de renovar os seus métodos de intervenção devido à complexidade, à diversidade das situações de intervenção e à ausência de políticas agrárias bem definidas.

As três instituições (Embrapa Semi-Árido, Emater-BA e Cirad) decidiram associar-se numa operação-piloto no distrito de Massaroca. A zona foi escolhida em função de um trabalho, que a Emater-BA realizava naquela localidade, de apoio à constituição de associações nas comunidades rurais.

A partir de 1987, as diferentes instituições mobilizaram uma equipe de três técnicos, engajados efetivamente na operação. Esta equipe foi complementada por outros técnicos, de acordo com as competências específicas que os trabalhos requeriam. A primeira fase desses trabalhos dedicou-se a um diagnóstico que permitiu caracterizar as dinâmicas agrárias.

\section{AS DINÂMICAS AGRÁRIAS}

\subsection{LIMITAÇÕES E POTENCIALIDADES DOS SISTEMAS DE PRODUÇÃO}

O distrito de Massaroca está situado no sertão baiano, a $70 \mathrm{~km}$ da cidade de Juazeiro-BA, uma das cidades mais antigas do interior do Nordeste, localizada em pleno polígono das secas. As secas são a tradução dos fenômenos climáticos, mas, também, de crises sociais e políticas.

Como todo o sertão, o distrito de Massaroca foi colonizado em decorrência da pecuária. Grandes latifúndios ocupavam o espaço. A crise das economias açucareira nordestina e mineradora no Estado das Minas Gerais reduziu a demanda em boi de tração à demanda de carne. Em conseqüência, minguaram as possibilidades de investimentos na atividade pecuária que predominava em todo o interior nordestino, principalmente, na região de influência do rio São Francisco. Isso ocasionou o desaparecimento, a partir de 1850 , de um expressivo número de grandes propriedades de pecuária extensiva.

Os vaqueiros das antigas fazendas de gado se instalaram nos espaços vazios deixados por elas. É interessante ressaltar que as comunidades atuais ainda carregam os nomes dessas antigas fazendas: Fazenda Lagoinha, Fazen- 
da Cipó, etc. O distrito de Massaroca é fruto desse processo de regressão da economia regional, que está intimamente associado ao declínio econômico da cidade de Juazeiro. Pouco a pouco, Massaroca entrou numa economia de auto-subsistência, baseada na pecuária de pequeno porte e numa agricultura de subsistência.

No decorrer dos anos, a população em crescimento se instalou na região em regime de autarquia. A atividade principal passou a ser a criação de caprinos, que foi possibilitada pela existência de vastas zonas de vegetação de propriedade comunitária: os fundos de pasto. Os filhos, normalmente numerosos, reproduzem, de modo idêntico, os sistemas de produção praticados pelos pais. O rebanho aumentou proporcionalmente à população humana até quando os recursos naturais disponíveis permitiram. Quando estes recursos se tornaram insuficientes, iniciou-se os tempos de crises, da migração para São Paulo e da descapitalização que leva parte da população à miséria. $\mathrm{O}$ sertão, em geral, e Massaroca, em particular, tornam-se um reservatório de mão-de-obra.

A migração teve conseqüências importantes:

- O contato com novas realidades se traduz numa vontade de "mudar as coisas";

- Um fluxo monetário rega a região. De volta à sua terra natal, os homens se casam, adquirem propriedades e investem. Os primeiros retornos coincidem com a expansão do uso do arame farpado na construção de cercas. Um pouco mais tarde, as culturas forrageiras perenes como algaroba (Prosopis juliflora) e capim buffel (Cenchrus ciliaris) se difundem. O mesmo ocorre com a palma forrageira (Opuntia sp.), que foi introduzida na região nos anos 50 .

As economias acumuladas em São Paulo, com o trabalho na construção civil, são usadas para a compra de terras, de animais e do arame farpado. Cercar, desmatar e plantar forragem são as ações centrais do processo de capitalização. Até que a propriedade ficasse consolidada, com uma reserva forrageira importante, a estratégia do agricultor estava sujeita ao fracasso caso a seca se prolongasse. Neste caso, a descapitalização era quase inevitável: seja pela descapitalização monetária, seja pela redução do rebanho e dos recursos forrageiros.

A dificuldade deste processo de capitalização se traduziu diretamente na tipologia dos produtores, que está ligada ao ciclo de vida dos mesmos e de suas famílias. Os produtores mais capitalizados, normalmente, são aqueles de idade média, que dispõem de mão-de-obra familiar. Mas, vale salientar que o capital disponível quase sempre não é suficiente para transmitir aos filhos, que devem, a cada geração, retomar o processo de capitalização.

A seca de 1979 teve como conseqüência a descapitalização da maioria das propriedades. Para os produtores que tinham conseguido comprar terras e animais, faltava-lhes o dinheiro para a infra-estrutura: cercas e aguadas, entre outras.

\subsection{ORGANIZAÇÃO E POLÍTICA PÚBLICA}

Retornar novamente para São Paulo em busca de oportunidades de emprego ou aproveitar as ajudas governamentais no Nordeste depois da seca eram o grande dilema da maioria dos agricultores? A igreja e as comunidades eclesiais de base e a recente intervenção da Emater-BA tinham estimulado os primeiros movimentos de organização dos produtores. Nove associações foram criadas no distrito de Massaroca entre 1982 e 1985 . A criação das associações de produtores dotou as comunidades de uma estrutura legal de representação. Fato que permitiu o acesso ao financiamento de equipamentos coletivos e individuais, viabilizados pelos programas de auxílio ou de desenvolvimento do governo federal. O principal deles foi o Programa de Apoio ao Pequeno Produtor Rural (PAPP), financiado pelo Banco Mundial e implementado pela $\mathrm{Su}-$ dene.

Apesar de todas as dificuldades, o projeto era inovador. Propunha-se a apoiar diretamente as associações e os produtores, com o objetivo de consolidar as estruturas comunitárias e as propriedades, financiando, principalmente, aguadas, cercas e forragens. O PAPP pretendia, também, inovar no domínio dos métodos e instrumentos de intervenção. Fazia, implicitamente, referências às teorias de Farming Systems, Pesquisa-Desenvolvimento e participação popular. A grande dificuldade era a implementação destas orientações por intermédio de técnicos que desconheciam, quase totalmente, esses princípios e métodos. No quadro do Programa, a Embrapa Semi-Árido ficou responsável pelo apoio metodológico às diferentes instituições dos sistemas estaduais de pesquisa e de extensão rural da região. Nesta perspectiva, Massaroca foi concebida, também, como um local de produção de referências, contribuindo para a divulgação e formação metodológica dos técnicos destas instituições.

Raízes, Campina Grande, vol. 22, nº 01, p. 88-98, jan.jun. 2003 
92 Jean-Philippe Tonneau e Pedro Carlos Gama da Silva

\section{ELABORAÇÃO DO PROJETO (1987-1988)}

\subsection{As ESTRATÉGIAS}

Para consolidar as associações, os técnicos das instituições envolvidas na região de Massaroca procuravam "contratualizar" as relações entre as comunidades, os municípios, o Estado e os seus órgãos, num plano de longo prazo, que traduziria perspectivas e ações prospectivas de desenvolvimento.

Pretendia-se, também, "quebrar" as antigas relações de clientelismo, típicas das práticas políticas adotadas na região nordestina. As ajudas obtidas deviam ser colocadas a serviço do desenvolvimento econômico da região. A finalidade principal era evitar na medida do possível, a repetição de projetos comunitários restritos aos aspectos sociais (saúde, educação, infra-estruturas). Os objetivos eram duplos: o reconhecimento das dinâmicas camponesas pelo Estado (sob as suas diversas formas) e a negociação com os seus serviços. A relação com o Estado e a sua estrutura de apoio ao desenvolvimento agropecuário era o centro das ações e de atuação que se pretendia.

Para aplicar estas orientações, foi escolhida uma abordagem de desenvolvimento, inspirada nas experiências francesas de planejamento local (Monet, 1976). A produção de informação e a sua difusão estavam no centro da estratégia e deviam favorecer os processos de aprendizagem individuais e coletivos. Foram, portanto, estes princípios que nortearam a primeira fase de elaboração do projeto (1987-89).

As etapas da elaboração e da realização desse projeto foram bem definidas: diagnóstico; elaboração de um programa de trabalho por meio de grupos de interesses; experimentação e difusão de inovações; acompanhamento e avaliação.

\subsection{O DIAGNÓSTICO PARTICIPATIVO}

O diagnóstico foi rápido e baseou-se na sistematização dos conhecimentos dos produtores e das observações dos técnicos, apoiando-se na análise do discurso do agricultor, na sua visão e percepção da realidade. O campo de estudo contemplou o conjunto da população e das suas atividades (a organização social, o meio natural, as unidades de produção, as relações com o exterior, etc.). Os principais resultados do diagnóstico foram:

- Um zoneamento da área de atuação (uso e vocação dos solos). A análise geo-ambiental foi experimentada pela primeira vez em Massaroca como instrumento metodológico a serviço do planejamento e da exten- são rural (Riche e Tonneau, 1989);

- Uma caracterização dos diferentes tipos de produtores (tipologia);

- Uma hierarquização dos problemas em função da diversidade dos meios físico e social, em particular das "estratégias de ação" diferenciadas segundo as zonas e os tipos de produtores.

\subsection{OS GRUPOS DE INTERESSE}

O grupo de interesse constitui uma estrutura de diálogo entre produtores, agentes de desenvolvimento e pesquisadores, acerca dos problemas identificados pelo diagnóstico. Para isso, vários grupos foram criados para formar os pólos de discussão, de intercâmbio e de experimentação em condições reais. Os grupos de interesse tinham como tarefas:

- a elaboração de um plano de intervenção, mobilizando os recursos materiais e humanos a partir de um problema identificado;

- o acompanhamento da execução das ações programadas, assim como a participação na avaliação e definição das modificações necessárias;

- a difusão da informação coletada e dos resultados do grupo para o conjunto dos membros da comunidade ou da organização local.

\subsection{O PROJETO GLOBAL DE DESENVOLVIMENTO}

Os temas discutidos nos diversos grupos de interesse resultaram na elaboração de um projeto de desenvolvimento global, cujas linhas centrais foram a criação e a validação de inovações técnicas, econômicas e organizacionais. Este projeto, sistematizado pela intervenção, foi discutido pelo conjunto da comunidade e dos parceiros externos. O projeto definiu as prioridades de trabalho e de financiamento, assim como a repartição dos papéis e das tarefas entre os diferentes atores. Em particular, formalizou a demanda dos produtores em relação à assistência técnica. Essa discussão permitiu, também, a harmonização das ações dos diversos grupos de interesse e das instituições envolvidas.

O projeto definitivo foi organizado em quatros eixos.

O primeiro eixo tinha como objetivo favorecer a transformação do espaço. Para isso, previa:

- realizar investimentos hídricos para cobrir as necessidades de água tanto da população como dos animais. A alocação destes investimentos devia permitir um melhor aproveitamento dos pastos;

- garantir a titulação individual e coletiva das terras; 
- facilitar a instalação dos jovens, mobilizando ajudas específicas;

- favorecer o processo de "cercar o espaço" (financiamento para arame e diminuição dos custos).

O segundo eixo relacionava-se ao aumento da produtividade dos sistemas técnicos agrícolas (variedades mais resistentes à seca, itinerários técnicos do tipo "dry farming" e irrigação, entre outros) e pecuários (manejo sanitário e alimentar do rebanho, manejo dos pastos etc.). Os objetivos do terceiro eixo por sua vez eram diversificar as atividades (apicultura, avicultura, artesanato, entre outras) e valorizar os produtos pela comercialização direta. Finalmente, o quarto eixo, "condução e manejo do projeto", pretendia desenvolver a capacidade dos agricultores de decidir o seu futuro. Foi previsto, inclusive, um dispositivo de monitoramento e de apoio às instâncias de decisão.

As ações do primeiro eixo, por sua vez, eram bem definidas, no entanto, as soluções exigiam, sobretudo, financiamento. Para os demais eixos, as ações eram mais difíceis e as soluções eram do domínio da pesquisa técnica ou institucional.

\section{UM PROCESSO ORGANIZATIVO}

\subsection{EXPERIMENTAÇÃO E ORGANIZAÇÃO}

Numa primeira fase do projeto, a maior parte das atividades, foi consagrada às experimentações técnicas que objetivavam assegurar as atividades de pecuária e criar pólos agrícolas intensivos (pequena irrigação, por exemplo). Esta orientação "experimental” não deve surpreender: a reflexão em torno da inovação técnica era o enfoque principal do projeto conduzido por uma instituição de pesquisa.

A partir destas experimentações se pretendia desenvolver um processo global de desenvolvimento que tratasse de questões técnicas, sociais, financeiras e organizacionais. Assim, um sistema de crédito, manejado pelo Comitê dos agricultores, permitiu financiar a instalação de superfícies forrageiras. A experimentação era percebida como um processo de aprendizagem que visava contribuir para a autonomia dos agricultores a partir de uma complexificação progressiva dos trabalhos.

As propostas técnicas identificadas pelos grupos de interesse foram as mais variadas. De Choudens (1992) levantou 24 inovações técnicas experimentadas no distrito de Massaroca: manejo animal (farmácia veterinária, pastagem rotativa, cerca elétrica); agricultura de sequeiro (va- riedades de milho, feijão e melancia; uso de adubos); novas espécies ou variedades forrageiras (guandu: Cajanus cajan; leucena: Leucaena leucocephala; capim buffel: Cenchrus ciliaris; palma forrageira: Opuntia sp.); técnicas de alimentação animal (feno, mineralização, raspa de mandioca); técnicas de irrigação com energia eólica (cata-vento) e hortifruticultura. Segundo a avaliação de De Choudens (1992), a adoção das propostas foi diferenciada. As tecnologias que demonstraram eficiência, ou seja, podiam se integrar na lógica dominante de ocupação do espaço, foram aceitas e mobilizaram os agricultores.

As hipóteses do trabalho foram confirmadas na primeira avaliação realizada em 1992. Segundo De Choudens (1992), a organização das comunidades é, neste momento, o resultado mais importante do projeto. Os sistemas de produção mais eficientes estão nas comunidades mais dinâmicas, em que a circulação da informação foi maior. Os inquéritos de opinião nas comunidades indicam que $75 \%$ dos produtores tinham uma opinião positiva a respeito das suas associações.

A principal manifestação deste sucesso organizacional foi a criação do Comitê de Massaroca. Esta criação foi motivada por uma viagem de intercâmbio de alguns dirigentes das associações comunitárias à França, cuja finalidade era visitar os agricultores da região de Montpellier, organizados no seio do Comitê des Hautes Garrigues. Ao retornarem da viagem, o Comitê das Associações Agropastoris de Massaroca (CAAM) é criado. O objetivo desse comitê é o de conjugar esforços das nove comunidades para implementar uma série de projetos de desenvolvimento de interesse global para a população da localidade, tanto do ponto de vista da produção agropecuária, como dos aspectos sócio-econômicos.

O Comitê teve a sua primeira atuação ligada ao projeto de crédito rural. Esta experiência foi possível graças à obtenção, junto à Cooperação Francesa, de um fundo financeiro rotativo. Em seguida, a divulgação da experiência de Pesquisa e Desenvolvimento, feita pelos órgãos de assistência técnica e de pesquisa, trouxe uma emissora de televisão nacional — a Rede Globo - a Massaroca, mostrando para todo o país, por meio do programa "Globo Rural", a experiência do Comitê. Isso reforçou a sua "legitimidade” em nível regional.

Este auge de reconhecimento coincidiu, também, com um momento de inflexão que daria início a um período de fraca atividade. A partir de 1991, as nove associações comunitárias entraram, de certo modo, num período de latência, para não dizer de regressão. Diver-

Raízes, Campina Grande, vol. 22, nº 01, p. 88-98, jan./jun. 2003 
sas causas foram identificadas para explicar esse problema. A centralização das decisões, das ações e das informações, que diziam respeito ao Comitê, foi a mais invocada. Houve, segundo muitos sócios, uma falta de circulação da informação do Comitê para as associações, e no interior dessas mesmas associações. As dificuldades de financiamento aparecem, neste momento, com o fim dos financiamentos comunitários do PAPP e com o sistema de financiamento do Comitê, que passou por problemas de gestão do fundo rotativo.

Enfim, depois de quatro anos de trabalho, as instituições ficaram preocupadas com as condições de difusão geográfica dos resultados. De fato, houve uma reorientação que afastou a equipe técnica de Massaroca, mas inspirou experiências pioneiras na região, como o Zoneamento Agroecológico do Nordeste (Silva et al., 1992); a Unidade de Planejamento Agropecuário Municipal de Juazeiro (Santana et al., 1994; Tonneau, 1994) e a Unidade Regional de Capacitação e Apoio ao Desenvolvimento Rural do Nordeste - URCA Nordeste (Caron, 1998; URCA-NE, 1994; Silva et al., 1995).

No mesmo período, entre 1991 e 1992, o projeto Massaroca passou por um processo de avaliação externa (De Choudens, 1992). Tratava-se de verificar a coerência dos métodos e dos resultados em relação aos objetivos iniciais do Projeto Global de Desenvolvimento e, eventualmente, de proceder às reorientações em função de evoluções específicas, erros ou mudanças de contexto. Neste período, foram desenvolvidos vários estudos para entender melhor as dificuldades dos processos como: os estudos da trajetória de desenvolvimento do distrito de Massaroca (Sabourin et al., 1996); o estudo sobre os sistemas de conhecimento local (Sabourin e Tonneau, 1998) e sobre as cadeias produtivas (Sautier et al., 1998). Apesar do interesse universitário, estes estudos não resolveram o problema principal: o enfraquecimento do Comitê.

\subsection{ANIMAÇÃO E GESTÃO}

Depois de dois anos de desestímulo, o trabalho de animação foi retomado. Uma série de fatores contribuiu para isso: os parceiros mudaram; a cooperação descentralizada com os agricultores franceses do Comitê des Hautes Garrigues começou em 1987 e viagens permitiram trocas de experiências que culminaram na criação de uma exploração agrícola nas zonas irrigadas, em 1992. Esta exploração agrícola tinha dois objetivos. O primeiro era pedagógico: formação dos jovens em técnicas de irrigação. $\mathrm{O}$ segundo era financeiro os lucros obtidos com os investi- mentos realizados pelos fundos de origens privada e pública; o apoio técnico dos agricultores franceses e o mercado financeiro, são reinvestidos nas comunidades. Transportes e escolas passaram a ser financiados com essas rendas e uma parte era consagrada à retomada do processo de animação da organização dos agricultores. Uma associação, a Associação de Desenvolvimento e Ação Comunitária do Vale do São Francisco — Adac, passa a ser responsável por esta animação.

As prioridades desta animação eram identificadas em termos de apoio à dinâmica associativa, de capacitação profissional, de autonomização das organizações locais e de reforço da capacidade de planejamento. Contrastando o não funcionamento das regras adotadas com o entusiasmo do processo de organização dos anos 198790, havia uma forte tentativa entre os técnicos de oferecer "novas regras", "soluções pré-fabricadas" ou, em outras palavras, receitas que se constituam em: um regulamento para o Comitê; cursos de associativismo; planilhas e calendários para o ressarcimento do crédito; plano de experimentação etc. Felizmente, o espírito do Projeto Global de Desenvolvimento continuava presente. E, apesar das mágoas recíprocas entre agricultores e técnicos, todos permitiriam o diálogo com o intuito de criarem juntos respostas para velhos e novos problemas.

Foi experimentado um sistema de planejamento participativo, baseado na atualização do diagnóstico das comunidades. Os mesmos princípios metodológicos adotados, desde o início do projeto, foram aplicados: a análise da situação e das necessidades; a restituição; a identificação/ hierarquização de problemas e soluções; a formulação de um plano local e, por fim, a reorganização da associação para executar o plano.

O processo foi implementado, essencialmente, a partir de assembléias em que eram convidados os membros da comunidade, sócios ou não da associação. Geralmente, eram necessárias, pelo menos, três assembléias ou sessões: uma para a restituição dos resultados da atualização do diagnóstico e do levantamento de necessidades; outra para a discussão dos problemas, hierarquização e procura de soluções ou propostas e, por fim, uma ou várias reuniões para transformar as propostas em planos operacionais. Nesta oportunidade, era lançada uma discussão sobre o papel e a responsabilidade da associação na execução dos planos e projetos.

O processo proporcionou uma conscientização a respeito da importância do acesso à informação, assim como, 
de sua circulação. Houve conseqüências na cobrança das diretorias, inclusive do Comitê. A nomeação de novos delegados da comunidade neste comitê foi um outro resultado.

Durante esse processo de definição de responsabilidades e de emancipação da organização local, houve um melhor entendimento das relações entre técnicos (Pesquisa e Desenvolvimento) e produtores e inclusive um esclarecimento das funções, do papel e dos limites de cada indivíduo.

\subsection{UMA NOVA PROGRAMAÇÃO}

A partir de 1994-95, os grupos de interesse reapareceram em Massaroca na forma de comissão, assim como, a retomada da reflexão sobre o futuro. Houve, ao mesmo tempo, uma dinâmica de abertura temática para outros aspectos do desenvolvimento rural (saúde, educação, gestão) e um processo de institucionalização da maioria das atividades das organizações, em particular do CAAM.

Quatro comissões foram criadas: crédito, lote irrigado, educação e equipamentos coletivos (caminhão, trator, etc.). Uma comissão de produção agropecuária não foi criada ainda, tendo as suas funções assumidas pela direção do Comitê. O referido comitê motivou novas atividades técnicas para as quais solicitou o apoio da pesquisa e da extensão. Houve, assim, um trabalho sobre a valorização econômica da pecuária (carne, couro e peles) e também sobre a pequena irrigação a partir de poços com motores elétricos e cata-ventos, que propiciou a valorização da melancia e do leite.

Paralelamente a estas atividades, a criação da Escola de Massaroca foi decisiva como suporte de animação. A escola foi concebida como um Centro de Educação Popular Integrada e tornou se, rapidamente, um meio privilegiado de realização de novas atividades. Ofereceu aos jovens, em primeiro lugar, oportunidades de educação, (assegurando-lhes completar a sua escolarização primária nos locais de residência por um custo baixo, continuando a trabalhar na exploração agrícola da família). As ações de formação profissional ou permanente permitiram a alguns jovens adquirir novas qualificações (agricultura, artesanato, serviços, gestão, entre outras) e permanecer na região com novas ocupações (artesão do couro, mecânico, queijeiro etc.). No entanto, foram as mulheres que, sobretudo, investiram e ocuparam este espaço de educação. Primeiro, pediram cursos de formação em matéria de artesanato e decoração (cerâmica, pintura sobre vidro e sobre tecidos, culinária, etc.). Estes cursos, desprezados pelos cônjuges, proporcionaram reuniões entre elas com um estatuto novo, sem o controle dos homens, mas com o apoio dos técnicos e educadores do centro de formação.

O trabalho das comissões, a qualidade da equipe pedagógica e o dinheiro proveniente do lote irrigado traduziram-se em um novo dinamismo. As comunidades reforçaram os laços internos e mobilizaram mais recursos externos. Posteriormente, a eletrificação modificou a vida cotidiana. O sucesso social é indiscutível, mas as melhorias foram, sobretudo, ligadas às transferências públicas coletivas (projetos sociais do governo) e individuais (essencialmente a aposentadoria). Em contrapartida o desempenho econômico foi menos evidente. É importante salientar que a avaliação do projeto deve ser feita considerando estes dois pontos.

\section{RESULTADOS E IMPACTOS DO PROJETO}

Medir os resultados e impactos do projeto de Massaroca é um exercício difícil, devido à complexidade e à heterogeneidade das ações efetuadas. Como medir e diferenciar o que está relacionado às grandes evoluções econômicas, aos dinamismos agrários e às ações do projeto, sobretudo, no Brasil do fim dos anos 80, onde a inflação atingia $150 \%$ por mês?

As condições de vida das famílias melhoraram; os recursos hídricos aumentaram; a eletricidade se difundiu; as casas foram renovadas ou aumentadas; a educação e os cuidados de saúde apresentaram mais êxitos. Poucas ou nenhuma destas modificações foi constatada nas comunidades não abrangidas pelo projeto. $\mathrm{O}$ reconhecimento dos produtores como força política progrediu. Os produtores souberam influenciar as ações desenvolvidas na região, tornando-se mais hábeis para mobilizar fundos e ajudas diversas. A organização dos produtores e o acesso à informação foram determinantes nesse processo devido ao interesse e à importância de espaços para o diálogo confirmaram-se.

$\mathrm{Na}$ sua primeira fase, o projeto centrou-se na apropriação dos recursos naturais pelo movimento de construção de cercas e de implantação de forragem. A estratégia era bem identificada e antiga. $\mathrm{O}$ projeto proporcionou a alavancagem desse processo: difundiu as soluções técnicas e garantiu os meios financeiros necessários. Entre 1987 e 1992, a superfície cercada duplicou.

O processo de fechamento do espaço exacerbou as diferenças sociais e foi bastante seletivo. Comparando as es-

Raízes, Campina Grande, vol. 22, nº 01, p. 88-98, jan.jjun. 2003 


\section{6 Jean-Philippe Tonneau e Pedro Carlos Gama da Silva}

truturas de produção entre 1987 e 1992, De Choudens (1992) demonstrou que a diferenciação dependeu, por um lado, da disponibilidade financeira e da força de trabalho na estrutura familiar de origem, que permitem as tomadas de risco e, por outro lado, do grau de adesão ao projeto. Os grandes produtores mobilizaram e monopolizaram os meios de produção, a terra e o crédito concedido aos que podem pagar independentemente dos riscos. A lógica do banqueiro foi adotada normalmente pelos responsáveis da gestão do fundo de crédito. Os líderes foram favorecidos pelos projetos. Os atores mais fracos, menos habituados a pensar o seu espaço para transformá-lo ficarão marginalizados.

Gradualmente, foram instaladas as leis da competitividade e da exclusão. As comunidades ficaram divididas entre dois objetivos contraditórios: a procura da competitividade necessária para o desenvolvimento econômico e a vontade de um desenvolvimento controlado. O diálogo social tornou-se difícil. Num primeiro momento, o projeto não conseguiu encontrar proposições alternativas para a estratégia de apropriação do espaço. A diversificação econômica não foi possível e, por fim, as experimentações com irrigação e apicultura, entre outras, não tiveram sucesso.

Foi pela retomada da animação, da discussão e do diálogo com todos os agricultores que se possibilitou à criação de novos campos de atividades econômicas e também culturais. Este resultado tornou-se possível, também, porque os recursos não faltaram e a aposentadoria corrigiu, de maneira durável, as distorções econômicas ligadas à competitividade.

\section{ENSINAMENTOS E RECOMENDAÇÕES}

Dois eixos de avaliação parecem impor-se. O primeiro refere-se à evolução do que pode ser chamado de processo interno: como reagem as comunidades em resposta ao desafio da integração? Como evoluem as regras e os hábitos sociais de solidariedade, circulação da informação e tomada de decisão? A experiência em Massaroca teve resultados positivos. A partir de uma pedagogia do "desenvolvimento", permitiu-se aos produtores o acesso a informações que confrontaram e afirmaram as suas estratégias de integração ao mercado. De Choudens (1992) mostrou a relação direta existente entre o acesso à informação, ao dinamismo e à melhoria da situação social. A importância das redes de proximidade e os sistemas de conhecimento, referente à divulgação das inovações foi confirmada.

O processo de desenvolvimento, também, contribuiu para a organização dos produtores e alterou, localmente, as relações tradicionais de dependência. As instituições e os serviços públicos evoluíram e passaram a considerar as necessidades e os desejos das populações locais. Entretanto, esse processo aumentou as diferenças sociais. A escolha inicial da integração ao mercado reduziu as possibilidades de autonomia ${ }^{2}$. É necessário que as formas de animação sejam reexaminadas. Pois a cumplicidade entre os líderes e a intervenção pode ser perigosa e o dinamismo, comprometido. Isso porque o processo não pode ser confiscado pelos líderes e técnicos e o papel da intervenção é garantir os questionamentos necessários para dinamizar as redes e evitar as ordens estabelecidas.

Perante esta necessidade de animação permanente, as instituições de Estado apresentavam limitações. Qualquer que seja a qualidade dos agentes, estes são prisioneiros das estratégias das instituições. Não é por acaso que o trabalho de animação, na segunda fase, foi realizado por uma ONG. Pois o segundo eixo de avaliação refere-se ao impacto real de operações voluntárias localizadas e limitadas no tempo, as quais podem ser constatadas nos grandes movimentos da história. A ação para a mudança social continua difícil e a sua avaliação não é fácil.

Esta avaliação oscila, freqüente e demasiadamente, entre uma visão pessimista e negativa quando compara os meios dos quais dispõe e os desafios que deve enfrentar e uma apreciação entusiasta, quando valoriza, as operações por motivos estratégicos. Mas restam alguns questionamentos: Qual é a representatividade deste tipo de operação em termos técnicos, econômicos, sociais e políticos? Qual é a importância dos acervos de experiências e como utilizá-los de maneira eficiente na definição das políticas públicas?

Imaginar e construir políticas de apoio à Agricultura familiar e, também, propiciar a aceitação por outros atores, significa organizar as relações econômicas, financeiras, sociais e políticas entre organizações camponesas e os outros atores. Há necessidade de estruturas de diálogo 
entre os diferentes agentes econômicos para elaborar, acompanhar e avaliar um plano de desenvolvimento regional harmonioso. O termo harmonioso é, provavelmente, ingênuo e utópico. Subentende a importância de se considerar as necessidades do conjunto da população, conciliando o curto prazo e o longo prazo, os interesses específicos e gerais. Estas estruturas devem estar, principalmente, em locais de formulação coletiva dos problemas para que seja viável a busca por soluções adequadas. A coordenação entre atores diversos (agricultores, industriais, investigadores, agentes de desenvolvimento e instâncias de decisões políticas) é essencial para construir novos mecanismos de regulação e tomada de decisões: a descentralização transforma o município local em um povo município no qual o diálogo entre os diferentes atores sociais é possível.

\section{CONCLUSÃO}

A dinâmica de organização das comunidades de Massaroca é marcada, sobretudo, pela capacidade de adaptação dos agricultores à evolução e à variabilidade das condições de produção. Portanto, não é nenhuma surpresa verificar uma capacidade de adaptação social frente às importantes mudanças institucionais e sócio-econômicas dos últimos 30 anos.

A análise dos processos da ação coletiva em Massaroca permite entender melhor a articulação entre transformações sociais, inovações técnicas e o contexto institucional, ou, em outras palavras, ação externa. As mudanças nas formas organizacionais, observadas em Massaroca, traduzem diversas formas de manejo da transição entre uma economia camponesa regulada pela reciprocidade de sistemas mistos e uma integrada aos mercados regional e nacional.

Apesar de dificuldades de acesso às informações, de problemas no manejo e na administração dos projetos ou de domínio das regras do mercado, foram obtidos importantes benefícios coletivos e individuais por meio da dinâmica de desenvolvimento local: infra-estrutura de educação, recursos hídricos, acesso ao crédito, assistência técnica e capacitação, dentre outros. Mas o maior ganho do processo de organização foi, seguramente, a aquisição da capacidade de construir e implementar projetos individuais e coletivos, mobilizando informação, recursos humanos e financeiros e equipamentos novos.

As experiências em Massaroca contribuem também, para identificar com precisão os eixos de atuação das ins- tituições de pesquisa e de desenvolvimento. Opõem-se ao discurso dominante de muitos políticos e de diversas instituições quanto à ausência, à fraqueza ou à incapacidade de organização dos pequenos produtores do Nordeste, habitual contraponto para justificar medidas emergenciais contra as secas e para explicar o inaceitável. O modelo de evolução das formas de organização proposto pelos agricultores de Massaroca oferece um quadro sobre qual ação pública poderia apoiar-se para conceber uma assistência técnica e financeira mais adaptada ao objetivo de fortalecer a agricultura familiar. Nesta perspectiva, o debate atual sobre a estratégia de desenvolvimento rural pode ser percebido como uma continuidade do trabalho de Massaroca.

\section{REFERÊNCIAS BIBLIOGRÁFICAS}

CARON, P. Espace, élevage et dynamique du changement: analyse, niveaux d'appropriation et actions. Le cas du Nordeste semi-aride du Brésil. 1998. these f. (Docteur en géographie) — Université Paris X-Nanterre. 396 f.

DE CHOUDENS, N. Etude de l'impact sur le terrain du projet de R/D de Massaroca Etat de Bahia, Brésil. Mémoire de fin d'études CNEARC/ESAT, Montpellier: CIRADSAR, 1992, p.70 p. + annexes.

KILIAN, J. Approche morphopédologique dans la région d'Ouricuri. Montpellier: IRAT/GERDAT; Petrolina: EMBRAPA-CPATSA, 1980. 29 p.

MONET, J. Mémoires. Paris: Fayard, 1976. v.2.

MONTOVANI, L.E; RICHE, G.; FOTIUS G., MIRANDA, E. E. Zoneamento agro-ecologico do tropico semi-arido: relatórios de pesquisas. Petrolina: EMBRAPA-CPATSA, 1986. 107 p.

RICHÉ, G.; TONNEAU, J.P. Stratification du milieu: l'exemple de Ouricuri. Cahiers de la Recherche Développement, Montpellier, n.24, 1989 p. 57-75, déc.

SABOURIN, E.; SILVA, P.C.G.; CARON, P. Estudo das trajetorias de desenvolvimento: contribuição metodológica para a analise das dinâmicas agrárias. Atelier Caravelle, Toulouse, n.7, p. 53- 72, sep. 1996.

Raízes, Campina Grande, vol. 22, nº 01, p. 88-98, jan./jun. 2003 
Jean-Philippe Tonneau e Pedro Carlos Gama da Silva

SABOURIN, E.; TONNEAU, J. P. Réseaux de proximité et diffusion des innovations techniques: le cas des communautés paysannes de Massaroca (Bahia, Brésil). In : Des protestantismes en lusophonie catholique. Paris: CEAN; Karthala: MPI. 1998, p. 67-89.

SANTANA, R. A. de; OLIVEIRA, J. de S.; CARON, P. $\mathrm{O}$ zoneamento por entrevista de pessoas chaves: proposta metodológica para subsidiar o planejamento municipal. In: CONGRESSO BRASILEIRO DE ECONOMIA E SOCIOLOGIA RURAL, 32, 1994, Brasilia, DF. Anais. Brasília: SOBER, 1994, v.2, 1073. p.

SAUTIER, D. e ali Diagnostic rapide de commercialisation des produits de l'agriculture familiale. In: SCOTT, G. GRIFFON, D. (Ed). Méthodes de marketing agro-alimentaire pour les pays en développement. Paris: CIRAD/CIP, 1998.

SILVA, F.B.R; RICHE, G.; TONNEAU, J.P.; SOUSA NETO, N. C. de; BRITO, L. T. de; CORREIA, R.C.; CAVALCANTI, A.C; SILVA, F.H.B.B da; SILVA A. B da; ARAUJO FILHO, J.C.; LEITE, A P. Zoneamento agroecologica do Nordeste: diagnostico do quadro natural e agrossocioeconomico. Petrolina, PE: EMBRAPA-CPATSA; EMBRAPA- CNPS - Coordenadoria Regional do Nordeste, 1993. v. 2. 1 mapa. (EMBRAPA-CPATSA. Documentos, 80).

SILVA, P.C.G.da; Diagnóstico rápido do sistema de comercialização e transformação do leite e derivados no município de Nossa Senhora da Glória-SE. Petrolina-PE: EMBRAPACPATSA, 1995. p.25. (Documento de trabalho).

TONNEAU, J. P. Modernisation des espaces ruraux et paysannerie: le cas du Nordeste du Brésil Nanterre. 1994. These (Docteur en Géographie). Université de Paris-Nanterre, $459 f$.

TONNEAU, J. P. Os SIP's: avaliação e ensinamentos. Petrolina, PE: EMBRAPA-CPATSA, 1987. p.37.

EMBRAPA. CPATSA. Unidade Regional de Capacitação e Apoio ao Desenvolvimento do Nordeste - URCA-NE (Petrolina-PE). Contribuição ao desenvolvimento regional: um desafio para URCA Nordeste. Petrolina, 1994. p.40. 